Nocardia asteroides التصالب المناعي بين جرثومتي و Salmonella typhimurium في القئران

محمد جويد علوان وميسون صباح عباس وسحر حسن علي وزينب عبد الزهره وحدة الامراض المشتركه-كلية الطب البيطري-جامعة بغداد-بغداد - العراق عان وعان

الخلاصه

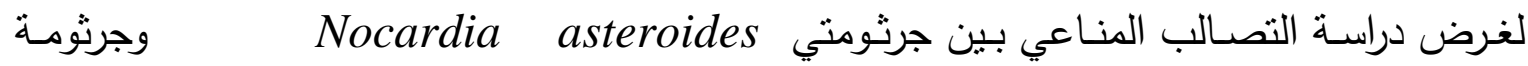
Salmonella typhimurium , استخدم 18 من الفئران البيضـاء السويسريه قسمت بصوره

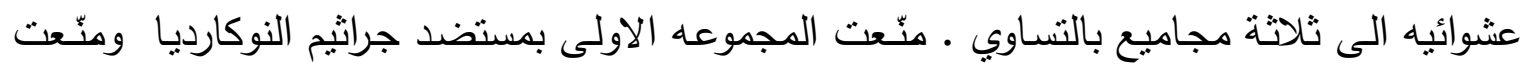
المجموعه الثانيه بمستضد جراثيم السالمونيلا وبعد اسبوع اعطيت نفس الجرعه كثقويه وبعد مرور شـهر مـن التمنيع تم اجراء فحص التحسس الاجل وفحص التلازن الانبوبي باستخدام مستضد النوكاردين والسالمونلين للمجموعتين. بينت النتائج ان الحيوانات الممنعه اعطت تفاعل ايجابي في قياس الاستجابه المناعيه الخلويـه والخلطيه تجاه كل من مستضد النوكاردين والسالمونلين مما يثير الى وجود تصالب مناعي بين مستضد جرثومة Nocardia asteroids وجرثومة Salmonella typhimurium. 


\title{
Cross Immunological reaction between Nocardia asteroides and Salmonella typhimurium in mice
}

\author{
Muhamed Juweed Alwan,Maysoon Sabah Abbas, Sahar Hasan Ali and \\ Zanab Abd Alzahra \\ Zoonosis unit- college of Vet. Med. - Baghdad university -Baghdad-Iraq
}

\section{SUMMARY}

The aim of this study was carried out to demonstrate the cross-immunity between Nocardia asteroids and Salmonella typhimurium antigens in mice. 18 mice, from both sex,were randomally divided into three groups equally. the first group immunized subcutaneously with 0.05 micrometer / animal of Nocardia asteroids antigen and abooster dose of the same antigen was injected after week of the first dose. The second group was treated as the first group with Salmonella typhimurium antigen. .The third group was served as non-immunized control group. Delayed hypersensitivity and tube agglutination test were checked at 30 days post-immunization. By using Nocardin and Sallmonelin antigens.

The results revealed that the animals were immunized with Nocardia antigens given agood immune response against nocardin and sallmonelin and also those animal were immunized with Salmonella antigens showed immune response against nocardin and sallmonelin antigen ,this may be indicated across- protection between Nocardia andSalmonella antigen .

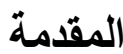

ان ظاهرة التمنيع المتبادل سجلت من قبل العديد من الباحثين حيث لهذه الظاهرة اثر واضح في في الهي رفع مستوى المناعه الخلويه في الجسم فلقد اوضح (1) وجود ظاهرة التمنيع المنبادل ين Listeria Brucella abortus Salmonella typhimurium و monocytogenes

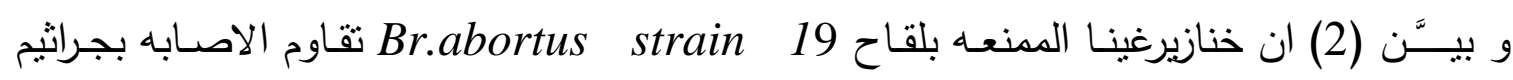

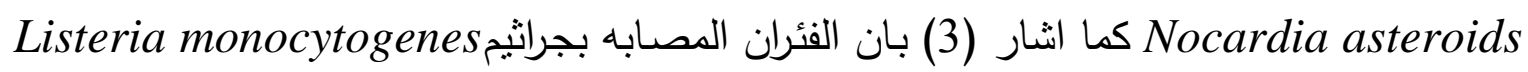
غير الضاريه تعطي مناعه جيده ضد الاصـابه بجراثيم Rhodococcus equi وكذلك لوحظ ان

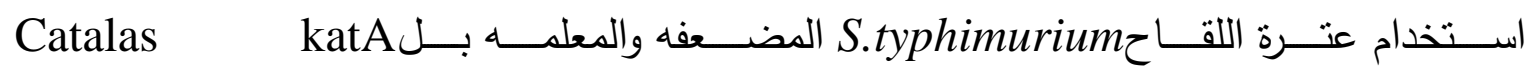

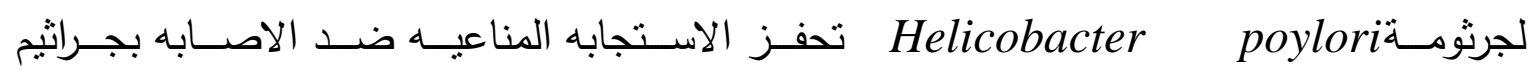
الا Helicobacter poylori

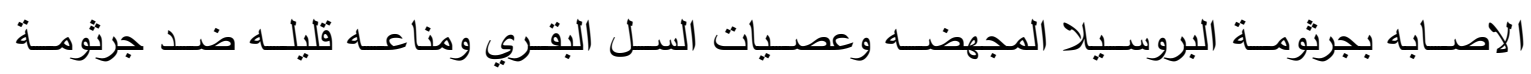


لاحظ الباحثون ان الخلايـا البلعميـه الفعاله المعزوله من الفئران

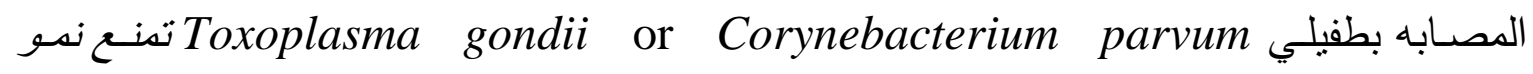

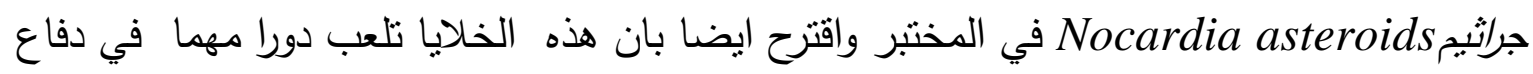

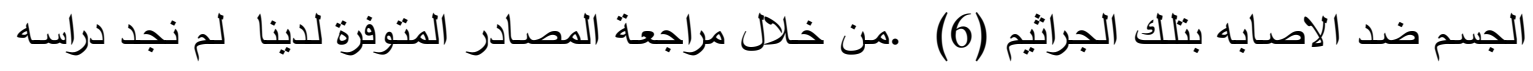

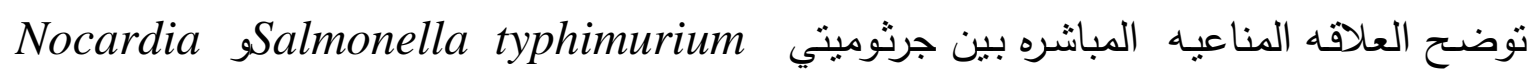
asteroids

\section{المواد وطرائق العمل}

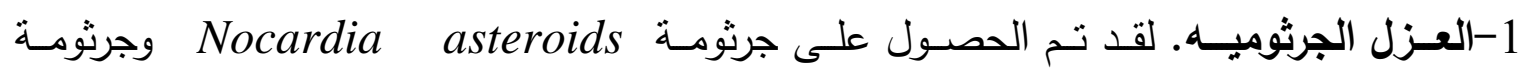
Salmonella typhimurium

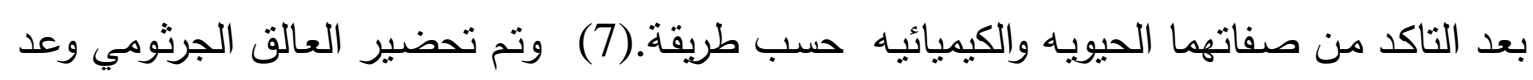

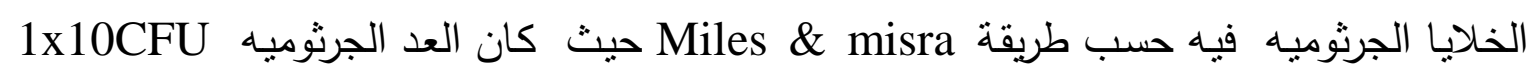
لجراثيم السالمونيلا وجراثيم النوكارديا . 2-الاوسـاط الزرعيه المستخدمه. استخدم وسط اكار الدم و وسط اكار السالمونبلا-شكيلا وقد حضرا حسب تعلبمات الثركة المنتجة.

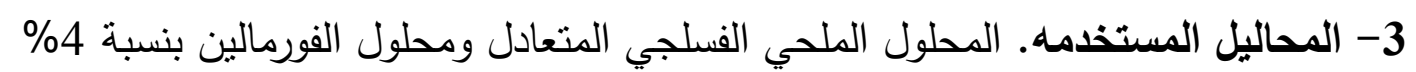
4-حيوانات التجريه. استخدم 18 من الفئران السويسريه البيضاء اللون بعمر 6 اسابيع وبمعدل وزن 20- 26 غم رتم الحصول عليها من معهد المصول واللقاح في بغداد.قسمت الحيوانات عشوائيا الى ثلاثة مجاميع بالتساوي وكما يلي:

1-المجموعه الاولى وعدد حيواناتها 6 حيوان, منعت بمستضد جراثيم Nocardia asteroids بلاثي"

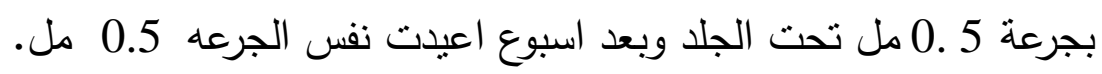

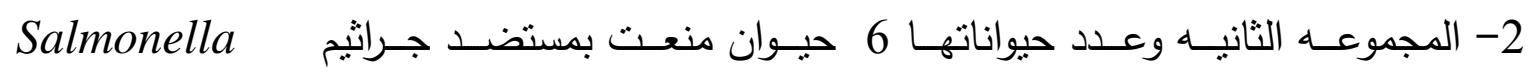

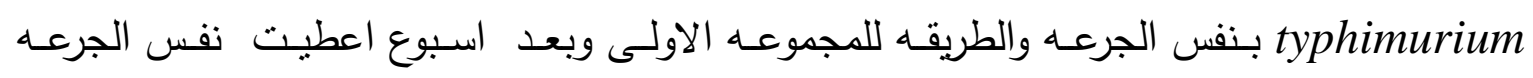
كثقويه.

3-المجموعه الثالثه وتتشمل 6 حيوانات اعتبرت حيوانات سبطره حقنت بجرعه 5 .0 مل من المحلول الفسلجي المتعادل المعقم تحت الجلد. 
تحضير المستضدات الجرثوميه

1- نم زرع جرثومتي Nocardia asteroids, Salmonella typhimurium على اكار الدم

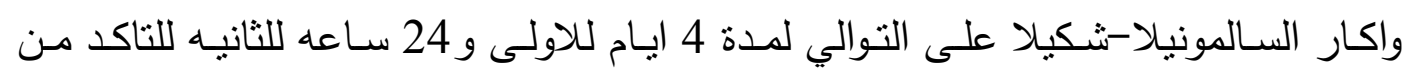
حيويةالجراثيم وقابليتها على النمو . 2- اخذت نماذج من الزرع الجرثومي وصبغت على شرائح زجاجيه وصبغت بصنئ بصبغة كرام للتاكد من نقاوتها وحيويتها.

3- حصدت الجراثيم باستخدام المحلول الملحي الفسلجي المتعادل وتم اجراء العد الجرثومي

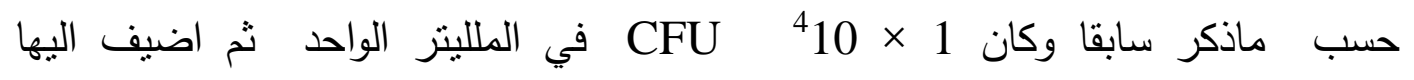
الفورمالين بتركيز4\% وتركت في درجة حرارة الغرفه لمدة 24 ساعه ثم غسلت بالمحلول الفسلجي المعقم ثلاث مرات للتخلص من الفورمالين ثم استخدم الجهاز المركزي الطارد درداد

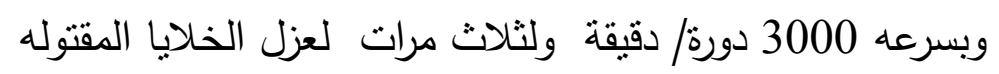

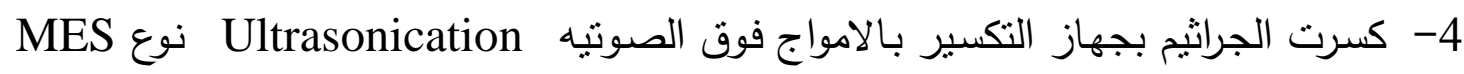
بسعه موجبه 3 وبقوه تعضيد متوسطه وتذبذب بمعدل 13 مايكروسبوت ولمدة 50 دقيقه منقطعه وقد وضعت بحمام ثلجي بجهاز تكسير الامواج فوق الصوتيه ثم فصلت الخلايا

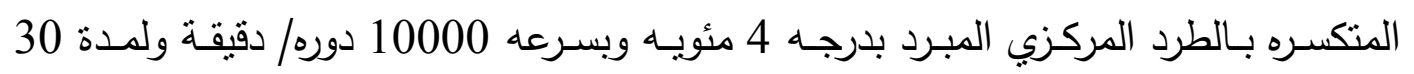
دقيقة. 5- رشح المحلول الطافي باستخدام مرشح زايتر وبحجم 0.45 ملي مايكرون لجرثومة النوكارديا

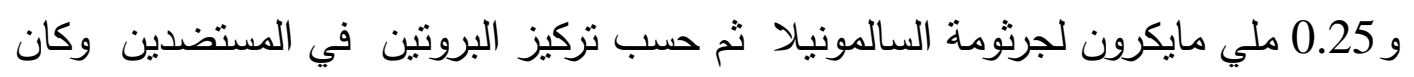
8ملغم/مل وبعد ذلك حفظت المستضدات بالثلاجه يدرجه 4 مئويه لحين الاستخدام. 6- نم اجراء فحص النقاوه للتاكد من نقاوة المستضدات لكل من جرثومني typhimurium and Nocardia asteroids Salmonella بزرعها على وسط اكار الدم ووسط اكار السالمونيلا-شكيلا وحضنها لمده 24و 48 ساعه ولم يسجل أي نمو جرثومي. قياس المناعه الخلويه بعد شهر من التمنيع تم اجراء الفحص الجلدي حيث حقنت راحة القدم اليمنى لكل حيوان في المجموعه الاولى والثانيه بالنوكاردين والسالمونلين على التوالي وحقنت راحة القدم اليسرى لكل حيوان

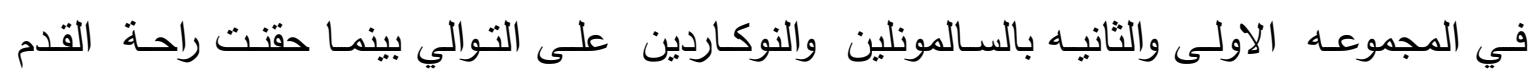


اليمنى لحيوانات السيطره السالبه بالنوكاردين وراحة القدم اليسرى بالسالمونلين وبجرعه 0.01 ملليلتر لكلا المستضدين ولكل المجاميع وتم اجراء قياس الفرق في سكك راحة القدم بعد 24و 48 ساعه. قياس المناعه الخلطيه

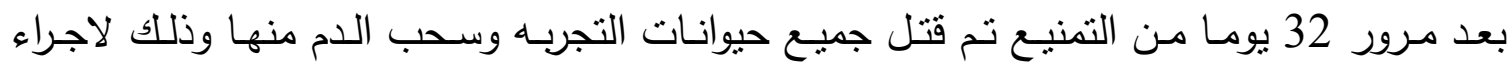
فحص التلازن الانبوبي لمعرفة مستوى الاجسام المضاده في الحيوانات المدنعه حيث فصل المصل

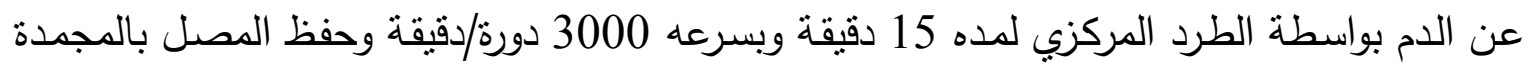
لحين الاستخدام استخدم مستضد النوكاردين والسالمونلين ضد مصل الحيوانات الممنعه بالنوكاردين

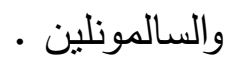

\section{النتائج}

\section{نتائج الاستجابه المناعيه الخلويه باستخدام فحص الحساسيه المتاخر} يبين الجدول (جدول1) نتائج الفحص الجلدي للمجموعه الممنعه بعد شهر من التمنيع بمستضد باسندابه

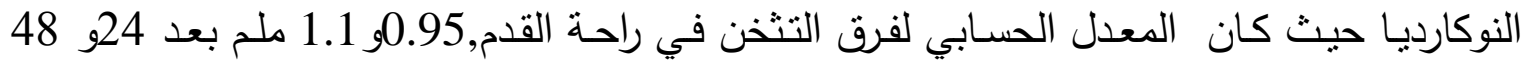
ساعه على التوالي من الفحص الجلدي تجاه مستضد السالمونلين و 0.71و 0.81ملم بعد 24و 48 ساعة على التوالي من الفحص الجلدي تجاه النوكاردين. بينما كان المعدل الحسابي لتنخن راحة ولنداه القدم في الحيوانات الممنعه بمستضد السالمونيلا98.01و 1.01ملم بعد 24و 48 ساعه على التوالي من

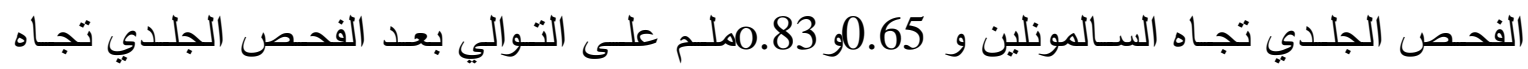

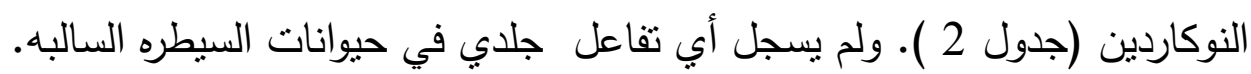
قياس مستوى المناعه الخلطيه توضح الجداول (4,3) المعيار الحجمي للاجسام المضاده في الحيوانات الممنعه بمستضد جراثيم Salmonella typhimurium باستخدام النوكاردين والسالمونلين Nocardia asteroides فلقد لوحظ ان الحيوانات الممنعه بمستضد جراثيم النوكارديا اظهرت معيارا حجميا تجاه السالمونلين بمعدل 213.3 وكذللك تجـاه النوكساردين بمعدل1066.6 امـا الحيوانـات الممنعـه بمستضـد جراثيم السـالمونيلا فلقــ كـان معـدا معيـار الاجسـام المضــاده533.3 تجـاه النوكـاردين و 693.3 تجـاه السالمونلين. لم تعطي حيوانات مجموعة السيطره أي تفاعل في الفحص الجلدي وفحص التنانن 
المجلة الطبية البيطرية العراقية، المجلد 32، العدد 1، السنة 2008

جلول (1): نتائج فحص التحس الاجل في الفئران الممنعه بمستضدجراثيم

Nocardia astroides

\begin{tabular}{|c|c|c|c|c|}
\hline \multicolumn{4}{|c|}{ معدل فرق التثخن(ملم) } & \multirow{3}{*}{ رقي } \\
\hline \multicolumn{2}{|c|}{ مستضد النوكاردين } & \multicolumn{2}{|c|}{ مستضد السالمونلين } & \\
\hline بعد 48ساعه & بعد 24ساعه & بعد 48ساعه & بعد 24ساعه & \\
\hline 0.5 & 0.5 & 1 & 1 & 1 \\
\hline 1 & 0.5 & 1 & 0.5 & 2 \\
\hline 1 & 1 & 1.5 & 1.5 & 3 \\
\hline 0.9 & 0.9 & 1 & 0.6 & 4 \\
\hline 0.5 & 0.4 & 1 & 1 & 5 \\
\hline 1 & 1 & 1.1 & 1.1 & 6 \\
\hline 0.81 & 0.71 & 1.1 & 0.95 & المعدل \\
\hline 0.20 & 0.18 & 0.27 & 0.23 & القياسي \\
\hline
\end{tabular}


المجلة الطبية البيطرية العراقية، المجلد 32، العدد 1، السنة 2008

جدول (2): فرط التحس الاجل في الفئران الممنعه بمستضد جراثيم Salmonella typhimurium والمقاسه بمستضد النوكاردين والسالمونلين

\begin{tabular}{|c|c|c|c|c|}
\hline \multicolumn{4}{|c|}{ معدل فرق التخن (ملم) تجاه } & \multirow{3}{*}{ رقم الحيوان } \\
\hline \multicolumn{2}{|c|}{ النوكاردين } & \multicolumn{2}{|c|}{ السالمونلين } & \\
\hline بعد48ساعه & بعد24ساعه & بعد48ساعه & بعد24ساعه & \\
\hline 0.5 & 0.5 & 1 & 1 & 1 \\
\hline 1 & 1 & 1.4 & 1.4 & 2 \\
\hline 1 & 0.8 & 1.4 & 1.4 & 3 \\
\hline 0.7 & 0.7 & 0.6 & 0.6 & 4 \\
\hline 0.8 & 0.8 & 1 & 1 & 5 \\
\hline 1 & 0.5 & 1. & 0.5 & 6 \\
\hline 0.83 & 0.65 & 1.06 & 0.98 & المعدل \\
\hline 0.20 & 0.18 & 0.26 & 0.24 & الخطأ القياسي \\
\hline
\end{tabular}

جدول (3) : المعيار الحجمي للاجسام المضاده باستخدام فصص التلازن الدموي المباثر في الفئران الممنعه بمستضد جراثيم N.asteroides والمقاسه بمستضد النوكاردين والسالمونلين

\begin{tabular}{|c|c|c|}
\hline \multicolumn{2}{|c|}{ معيار الاجسام المضاده } & \\
\hline السالمونلين & النوكاردين & \\
\hline 80 & 640 & 1 \\
\hline 80 & 640 & 2 \\
\hline 320 & 1280 & 3 \\
\hline 160 & 1280 & 4 \\
\hline 320 & 1280 & 5 \\
\hline 320 & 1280 & 6 \\
\hline 213.3 & 1066.6 & المعدل \\
\hline 52.064 & 260.24 & الخطأ القياسي \\
\hline
\end{tabular}


جدول(4): المعيار الحجمي للاجسام المضاده باستخدام فحص التلازن الدموي المباشر في الفئران الممنعه بمستضد جراثيم Salmonella typhimurium والمقاس باستخدام مستضد السالمونلين

\begin{tabular}{|c|c|c|}
\hline \multicolumn{2}{|c|}{ معيار الاجسام المضـاده } & \multirow{2}{*}{ رقم الحيوان } \\
\hline النوكاردين & السالمونلين & \\
\hline 320 & 640 & 1 \\
\hline 640 & 128 & 2 \\
\hline 640 & 640 & 3 \\
\hline 320 & 320 & 4 \\
\hline 640 & 640 & 5 \\
\hline 640 & 640 & 6 \\
\hline 533.3 & 693.3 & المعدل \\
\hline 130.12 & 86.59 & الخطأ القياسى \\
\hline
\end{tabular}

\section{المناقشه}

اوضحت نتائج فحص فرط التحسس الآجل والمعيار الحجمي للاجسام المضادة بأن مستضد جرثومة Salmonella typhimurium وجرنا Socardia asteroides وخلطية في الفئران بعد 30 يومآ من تمنيعها بتلك المستضدات ـ ان مستضد السـالمونيلا حفز

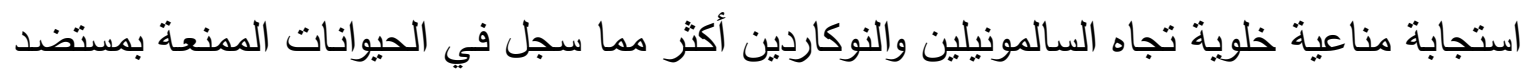
النوكارديا بينما حفز مستضد جرثومة النوكارديا استجابة مناعية خلطية تجاه النوكاردين أكثر مما فياه

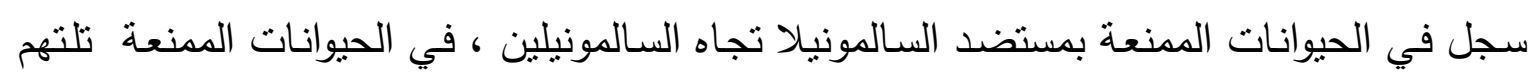


المستضدات من قبل البلاعم الكبيرة وتحطمها داخل الخلية بعدها تتقل اجزاء صغيرة من هذا الحطام

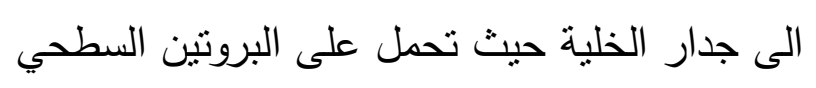

Major histocompatability complex II

$$
\text { - } \mathrm{IL}_{1}, \mathrm{IL}_{12}, \mathrm{IL}_{10}
$$

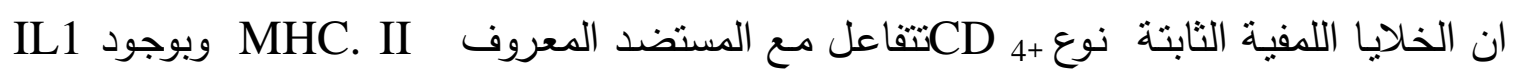

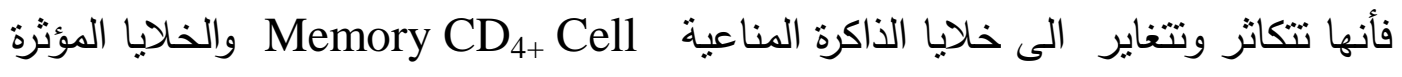
IL وكذلك الانترفيرون كاما T-helper Cell

$$
\text { الذي يعمل على تحفيز وتتشيط البلاعم الكبيرة ( (8) . }
$$

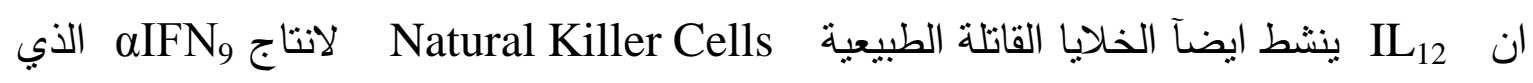

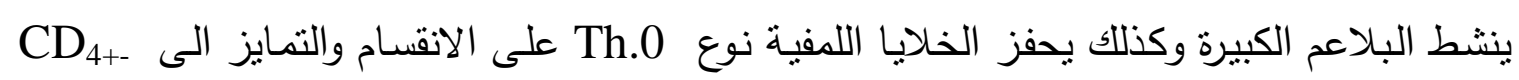

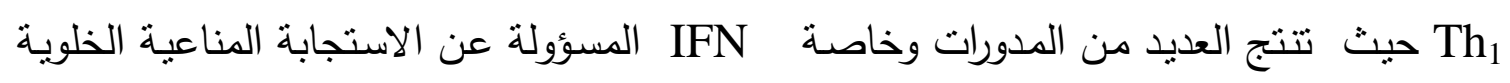

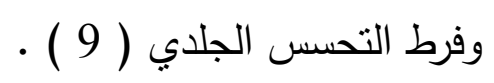

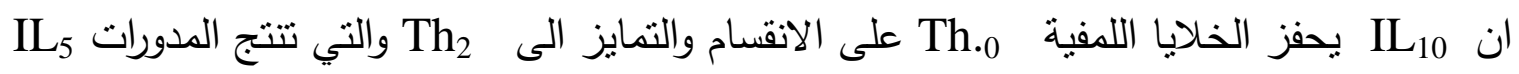
و م- على التكاثر والتمايز الى خلايا البلازما

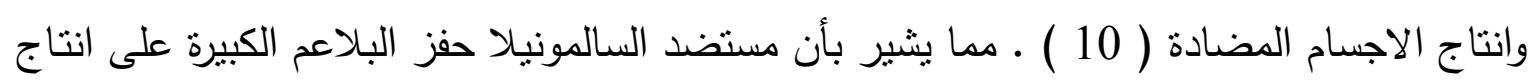

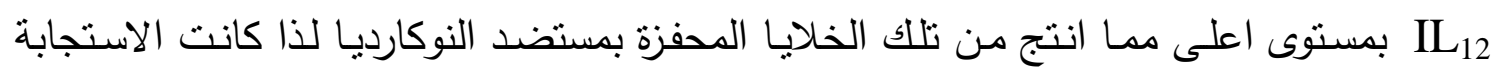

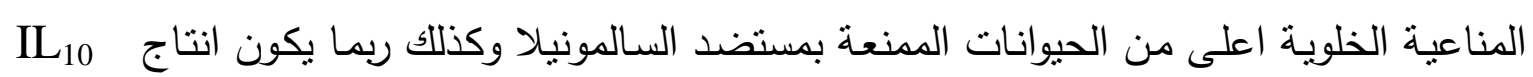
من قبل البلاعم الكبيرة المحفزة بمستضد النوكارديا اعلى مما حفز استجابة مناعية خلطية اعلى من

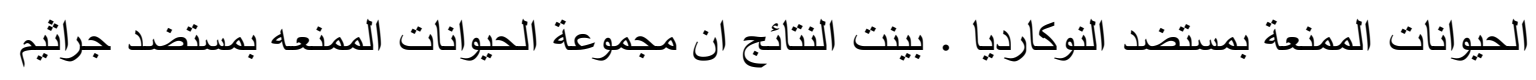

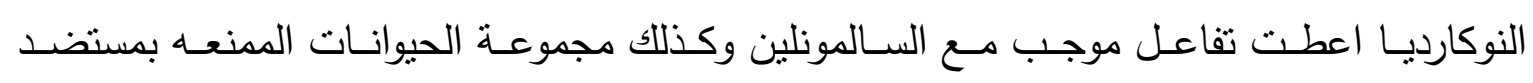

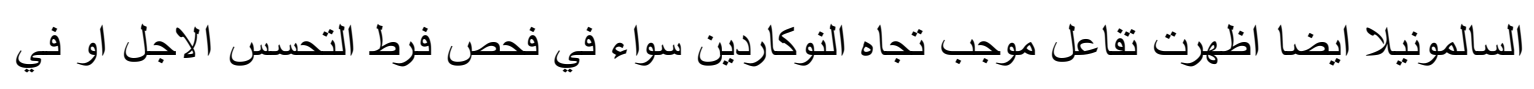

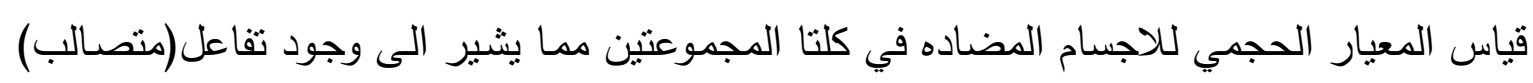

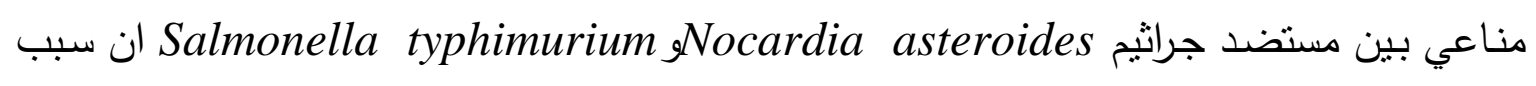
ذلك لربما يعود امـا الى التحفيز الدناعي غير المتخصص او ان هنالتك تنسابه بين مستضدات

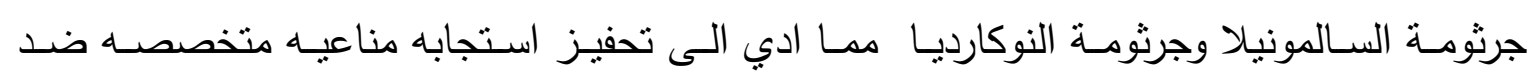

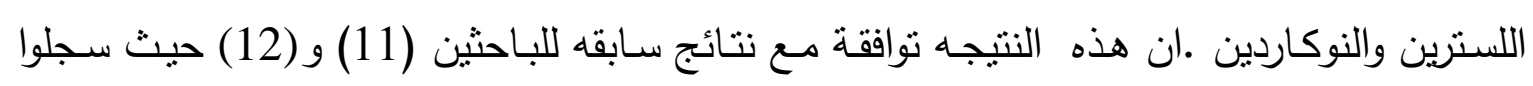
تصالب مناعي بين جراثيم

Listeria monocytogenes,Brucella abortus and Mycobacterium tuberculosis وعللوا ذلك بسبب وجود تثابه في بعض المستضدات بين هذه الجراثيم كذلك بين (13) ان استخدام 
مزيج من مستضد جراثيم النوكاريا مع مستضد البروسيلا المجهضه حفز استجابه مناعيه افضل من

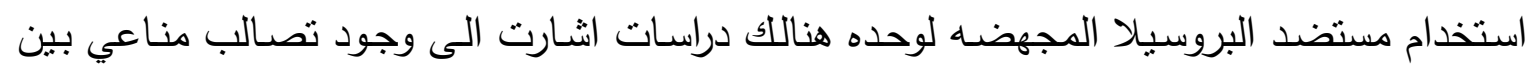

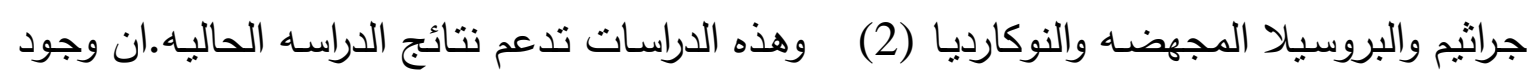

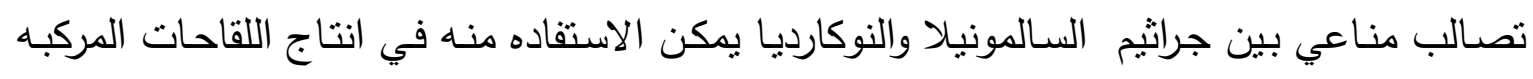

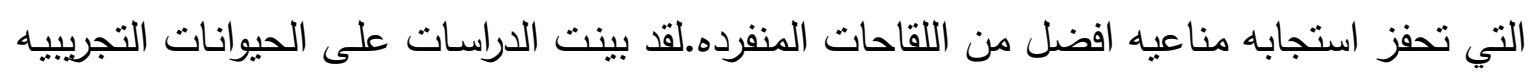

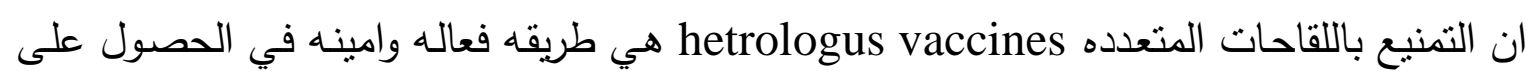

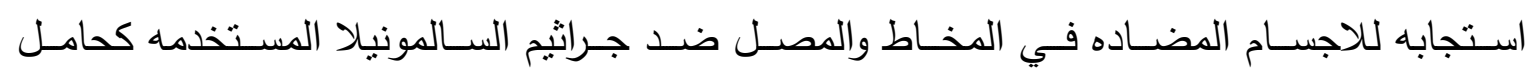

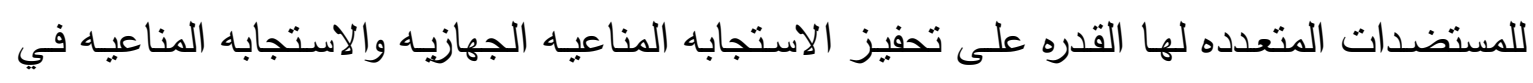

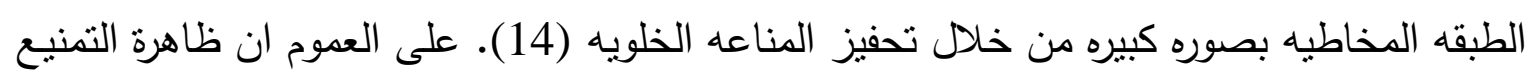

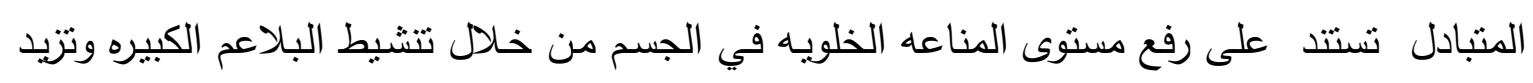

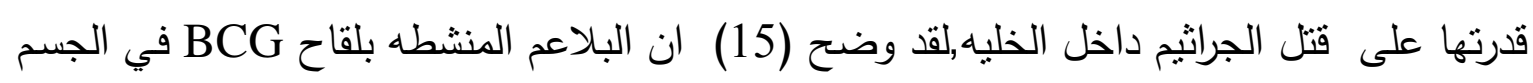

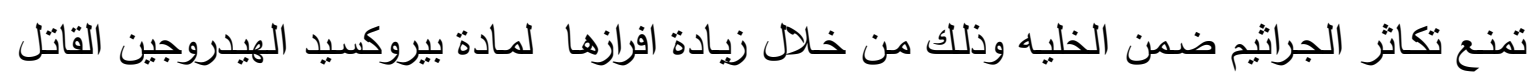

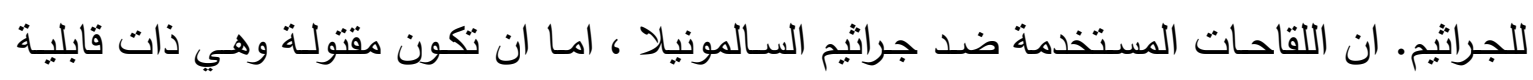

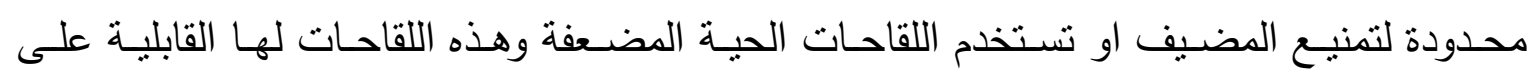

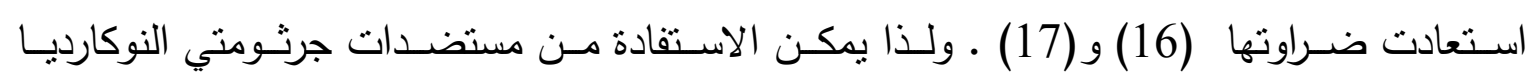

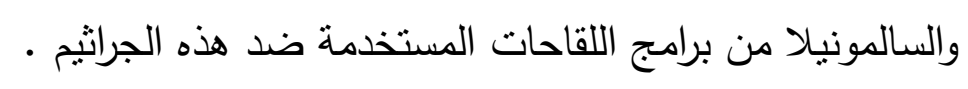
ان جراثيم السالمونيلا وجراثيم النوكارديا هي جراثيم ضمن الخليه تتنقل من منطقة الاصيابه بواسطة الخلايا البلعميه الى العقيدات اللمفيه الموضعية ومنها الى المجرى الدموي لنستقر في خلايا الجهاز

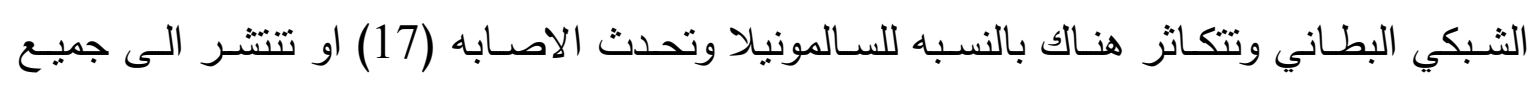

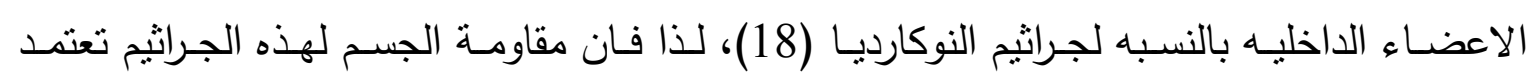
بالاساس على الاستجابه المناعيه الخلويه(19).

\section{المصادر}

1-Krick J A and Remington J S . Resistanc and with Nocardia asterodes. J. .Dis;(1975).131:665-675 .

2-Alwan M J .(1996).Study of some aspects of Nocardia asteroids in Iraq, Ph.D. Thesis, College of Vet.Medicie,University of Baghdad. 


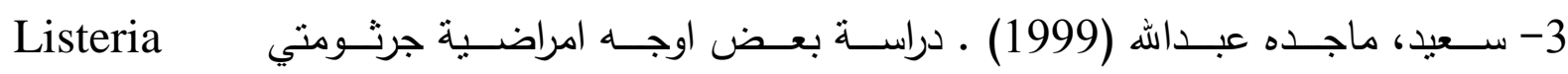

Rhodococcus equi gmonocytogenes

$$
\text { ماجستبر ،كلية الطب البيطري ، بغداد. }
$$

4-Liao W,Chen N,Zhu, Zhoughua Y and Zhi Z.(2001)Construction of attenuated Salmonella typhimurium vaccine strains expressing Helicobacter pylori catalase and observation on its protective immunity Vaccin.;81:613-626.

5-الجبوري،نغم محمد(2002). تاثير التمنيع المنبادل باللستيريا مونوساينوجين على مرضية جراثيم داخل

$$
\text { الخليه الاخرى.رسالة ماجسنير ،كلية الطب البيطري، بغداد. }
$$

6-Gregory A F,Beaman B L and Remingiten J S.( 1980)Effect of activated macrophages on Nocardia asteroids.Infect.Immun.;27:643-645.

7-Qunin P J,Crter M E,Markey B and Carter C R.Clinical Vet.Microbiol. 1994;156-169 M Wolfe.London.

8-Taylor,G.A.;Freng,G.C and Sher, A.(2004) Regulators of immunity \& intracellular pathogens .Nat.Rev. Immunol. ;4:100-109 .

9-Bregenholt,S.;Berche,P. and Disanto,J.D.( 2001). Conventional $\alpha, \beta \quad$ T- cells are sufficient for innate and alaptive immunity against enteric Listeria monocytogenes . G. Immuno.; 166:1871-1876 .

10- Velikovsky,C.A.;Cassataro, J.(2002);Giambartolomie, G.H.; Goldbaum, F.A. and Spitz,M. A DNA vaccine encoding Iumazine synthase protective immunity in BALB/Cmic. Klent. Immun. ;70 :2507-2511 11-Elberg S S , Schneider F and Frong J .Cross-immunity betweBrucella melitensis and Mycobacterium tuberculosis.Intracellular behavior of brucella melitensia in monocytes from vaccinated animals.J.Exp.Med. 1957;106:545-554.

12-Minden P , McClatch J K and Farr R S(1972).Shared antigens between hetwerologous bacterial species.Infect.Immun.;6:574-582.

13-Khalifa K A , Amin A and Jergees J I(1994).Effect of Nocardia on the immune response to brucella.Iraq,J.Micro.;6:6-23.

14-Holger R , Emeka II , Saur J , Hardt W, Wubert A and Geginat G .( 2001) Protection against Murine listeriosis byoral vaccination withRecombinant Salmonella expressing Hybrid Yersinia type III proteins.J.Immunol. ;167:357-365.

15-Beaman B L and SSmathers M.(1976)Interaction of Nocardia asterodies with cultural rabbit alveolar macrophages.Infect.Immun.;13:1126-1131.

16-Masteronie, J.A .; Harrison, C. E . and Hormaeache , A.( 1994) Natural resistance and acquired immunity to Salmonella .Fundamental and clinic. Immunol, ; 2:83-94 .

17-Sebastian G,Blais V,Veronique S U and Stevenson M.( 2002) Host immune response to Salmonella enterica serovar typhimurium infection in mice from Wild strains.Infect.Immunol.;70:1997-2009. 
18-Beaman B L,Burnside J,Edward B and Causely W(1976).Nocardial infection in the unite state 1972-1974.J.Infect.Dis.;134:286-290

19-Chollin F(1974).Vaccins and cell mediated immunity,.Bacteriol.Rev.; 38:371-402. 